(2) Open Access Full Text Article

\title{
Immunoglobulin transfusion in hemolytic disease of the newborn: place in therapy
}

\author{
This article was published in the following Dove Press journal: \\ International Journal of Clinical Transfusion Medicine \\ 18 June 2015 \\ Number of times this article has been viewed
}

\section{Cynthia A Mundy \\ Jatinder Bhatia}

Department of Pediatrics, Division of Neonatology, Georgia Regents University, Children's Hospital of Georgia, GA, USA
Correspondence: Cynthia A Mundy Department of Pediatrics, Division of Neonatology, Georgia Regents University,

II 20 I5th Street, BIW 6033,

Augusta, GA 30912, USA

$\mathrm{Tel}+\mathrm{I} 7068325885$

Fax +l 7067218638

Email cmundy@gru.edu
Abstract: Hemolytic disease of the newborn continues to be a common neonatal disorder that requires a comprehensive understanding on the part of those caring for infants. Common treatments include hydration and phototherapy. Exchange transfusion is used in severe hemolytic disease, but infants undergoing this treatment are exposed to many adverse effects. Intravenous immunoglobulin is a newer strategy that is showing promise in the treatment of the disease. This review discusses the current use and future expectations of intravenous immunoglobulin therapy in newborns.

Keywords: hyperbilirubinemia, ABO incompatibility, neonatal jaundice

\section{Introduction}

Various treatment modalities are available for the management of isoimmune hemolytic disease (HD) of the newborn, including administration of intravenous immunoglobulin (IVIG). Neonatal use of IVIG to treat hemolytic anemia was first reported in 1987 by Hara et al as being successful in the treatment of late anemia due to rhesus E incompatibility. ${ }^{1}$ Since that time, numerous reports have been published discussing its use in other forms of HD of the newborn, mainly blood group incompatibility, which has proven effective and reduced the need for more invasive treatments such as exchange transfusion..$^{2-10}$ This paper discusses the current use of IVIG as a treatment for neonatal HD and future uses, including fetal administration.

\section{Overview of hemolytic disease of the newborn}

Hemolytic disease of the newborn falls into three basic categories based on cause and serological diagnosis, ie, Rh disease, ABO blood group incompatibility, and alloantibody reactions. Rh disease is managed by maternal administration of Rho(D) immune globulin which binds to and destroys fetal cells circulating in maternal blood before a full maternal immune response can be initiated. ${ }^{11}$ Additionally, use of Doppler ultrasound to diagnose fetal anemia and treatment with intrauterine transfusion has significantly reduced the rates of infants born with significant Rh disease. ${ }^{10}$

Blood group incompatibility occurs in 15\%-25\% of pregnancies. ${ }^{12-14}$ Mothers with the blood group O-positive develop anti-A and anti-B antibodies. If a fetus is A or B blood type, an incompatibility exists and maternal anti-A or anti-B antibodies attach to the fetal blood cell, leading to destruction and the development of jaundice and anemia. However, only one in 150 infants develop mild hemolysis and even fewer, one in 3,000 , develop severe disease. ${ }^{13}$ 
Rare alloantibodies, including anti-D, anti-c, anti-E, antiKell, anti-Kidd, and anti-Duffy, can also lead to hemolytic anemia in the newborn. ${ }^{15}$ Of these, anti-D remains the most common, affecting 1 to 1,200 pregnancies. ${ }^{16-18}$ Prenatal maternal testing can identify these antibodies, so health care providers can provide close monitoring and possible prenatal interventions. ${ }^{15}$

\section{Diagnosis of hemolytic disease}

To identify infants who may be at risk for development of HD not known prenatally, blood typing and the direct antiglobulin test (DAT, or Coombs test) are completed. The DAT identifies antibodies that are attached to the infant's red blood cells, indicating an immune-dependent reaction. ${ }^{15,19}$ The test will be positive regardless of the antibody type (anti-A, anti-B, or the rarer alloantibodies discussed above). It was previously believed that the severity of the infant's disease correlated with the DAT being positive, but recently the DAT has been shown to have a poor positive predictive value in identifying infants who needing treatment. ${ }^{15}$ It was shown that only $23 \%$ of infants with a positive DAT required phototherapy. However, it was also demonstrated that the stronger the positive result, the more likely the infant was to require treatment. ${ }^{20}$ False positive results can occur from Wharton's jelly contaminating the sample. ${ }^{19}$

A complete blood count is also necessary in the evaluation of HD. Depending on the timing of the study, anemia may be mild or severe. Reticulocytosis and an elevated nucleated red cell count as well as spherocytosis will often be present as the infant attempts to correct the anemia by generating new, immature red blood cells. ${ }^{11}$

As the red blood cells are destroyed, bilirubin is released and the infant's immature liver is unable to conjugate the large bilirubin load. Without removal in the gastrointestinal tract, the bilirubin levels rise, leading to clinical manifestation of jaundice within 12-24 hours of birth. ${ }^{14}$ The initial anemia and subsequent hyperbilirubinemia are treated within the first week of life. However, chronic anemia often develops and should be followed-up at 6-8 weeks of life.

\section{Treatment of hemolytic disease}

The goal of any therapy is to treat the etiology of the disease using the most effective but least invasive method. Several treatments are available for the management of HD of the newborn, including enteral or intravenous hydration, phototherapy, exchange transfusion, and IVIG. Hydration and phototherapy have been safely used as a standard practice and are not discussed in depth here. Exchange transfusions are briefly discussed, but the main focus is on use of IVIG for management of HD.

Exchange transfusion has been used as a treatment for severe HD with hyperbilirubinemia unresponsive to phototherapy. ${ }^{15,21}$ Guidelines have been developed dependent on bilirubin levels at a specific hour of life and the rate of rise of these levels. ${ }^{21}$ Additionally, the general guideline of severe anemia (hemoglobin $<10 \mathrm{~g} / \mathrm{dL}$ at birth) and/or severe hyperbilirubinemia in the first 48 hours of life have been suggested as to when an exchange should be performed. ${ }^{15}$ The procedure is effective, with approximately $25 \%$ of the bilirubin removed. ${ }^{22}$ Adverse effects of exchange transfusion are numerous and include acid-base instability, apnea, catheter-induced issues (cardiac arrhythmias, embolism, thrombosis, infection), electrolyte imbalances (hypocalcemia, hypoglycemia, hypomagnesemia), necrotizing enterocolitis, bowel perforation, pulmonary hemorrhage, and thrombocytopenia. ${ }^{23}$ Due to these adverse effects, providers have been evaluating less invasive treatment strategies, such as IVIG.

Several IVIG solutions are commercially available and package inserts should be read carefully to ensure proper administration prior to use. Gammagard Liquid ${ }^{\circledR}$ (immune globulin infusion, human) $10 \%$ is discussed here as one preparation. Most preparations contain IVIG as a sterile, purified liquid preparation of pooled and concentrated human immunoglobulin (Ig)G antibodies (small amounts of IgA and $\operatorname{IgM}$ is also present). Donors are tested for hepatitis B surface antigen and antibodies to human immunodeficiency virus 1 and 2 and hepatitis $C$ through donation sites approved by the US Food and Drug Administration. The $\mathrm{pH}$ of the solution is 4.6-5.1 and the osmolality is $240-300 \mathrm{mOsmol} / \mathrm{kg}$. ${ }^{24} \mathrm{IVIG}$ "contains a spectrum of antibodies capable of interacting with and altering the activity of cells of the immune system as well as antibodies capable of reacting with cells such as erythrocytes". ${ }^{24}$ When HD occurs, maternal antibodies present in the infant's blood attach to the antigen receptors on the infant's red blood cells. Specifically, the maternal antibody attaches its Fc region, the lower portion of the antibody, to specific immune system cells, such as macrophages, stimulating the destruction of the antigen-antibody complex and the red blood cell. ${ }^{25}$ It has been proposed that IVIG blocks the Fc receptor and therefore blocks the binding of the antibody to the antigen. ${ }^{26-28}$ With this blockade, hemolysis no longer occurs.

The dose of IVIG for management of HD is $500 \mathrm{mg} / \mathrm{kg}$ to $1 \mathrm{~g} / \mathrm{kg},{ }^{21}$ and it should be infused through a dedicated line after preparation in the pharmacy. Figure 1 provides a 


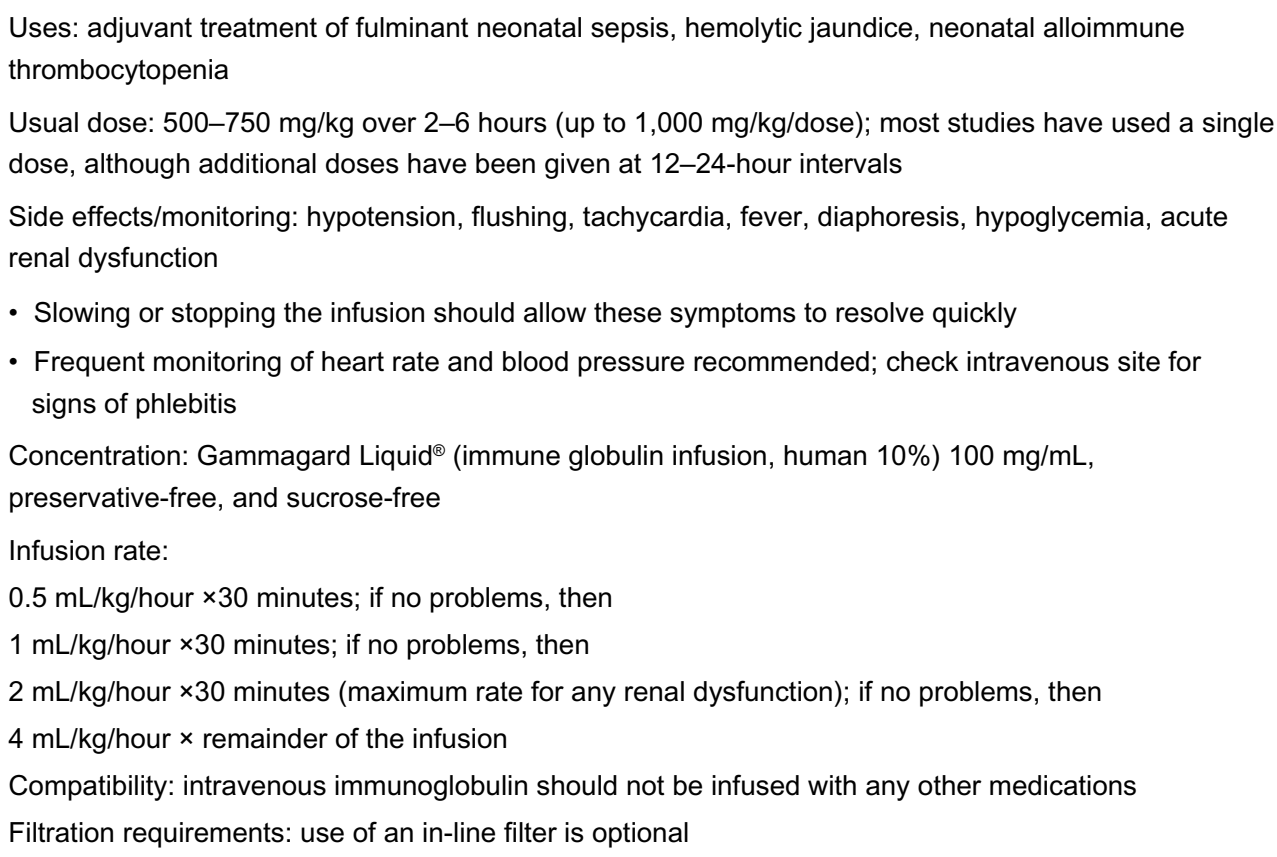

Figure I Intravenous immunoglobulin administration protocol used at the Georgia Regents University, Children's Hospital of Georgia.

sample protocol for IVIG administration. While single-dose therapy has been most commonly reported, case studies are demonstrating that multiple doses can be safe and effective in infants who continue to display HD after the initial dose. $^{8,11}$

IVIG has been deemed safe, and is generally well tolerated with a limited side effect profile. ${ }^{28} \mathrm{Hemolysis}$, acute renal failure, and sepsis in preterm infants have been reported. ${ }^{29,30}$ More recently, an association with necrotizing enterocolitis has been described, but other factors in the development of necrotizing enterocolitis, such as prematurity and prenatal risk factors, could not be ruled out. ${ }^{10,31-33}$

\section{Discussion}

IVIG has been demonstrated to be a safe and effective treatment for HD of the newborn, with no major side effects reported in neonates. ${ }^{15}$ IVIG has been studied by the Cochrane Collaboration, which found that it significantly reduces the need for exchange transfusions. However, since the studies evaluated were small and of limited quality, further studies were recommended before drawing conclusions. ${ }^{29}$

Most studies have compared IVIG with the need for exchange transfusion and almost all have found a reduction..$^{3-10,29}$ Only Smits-Wintjens et al showed that exchange transfusion rates were not decreased by use of IVIG, but this study population had a high rate of intrauterine transfusions which may be the reason for the discrepancy. ${ }^{10,34}$
The American Academy of Pediatrics recommends IVIG, with repeat dosing if necessary, as an adjunct therapy in the management on HD of the newborn. ${ }^{21}$ Corvaglia et al also demonstrated that IVIG may decrease the risk of neurological impairment because IVIG decreases time in the high-risk zones on the Bhutani nomogram. ${ }^{10}$ Length of stay data have been collected, but have been inconclusive. ${ }^{10,35,36}$

\section{Implications for the future}

Several reports have demonstrated positive results regarding the use of IVIG as a fetal therapy. In 2007, Kriplani, et al reported four cases in which IVIG was administered at the time of an intrauterine transfusion. All four cases showed a reduction in need for additional intrauterine transfusions and post-natal exchange transfusion rates. ${ }^{37}$

Matsuda et al reported a case of severe fetal anemia treated with an injection of IVIG into the fetal abdominal cavity. Four treatments were administered, and no side effects were noted. The infant was reported as healthy, with no exchange transfusion or phototherapy required. No chronic anemia or developmental delay was noted at 12 months of life. ${ }^{38}$

Most recently, Bellone and Boctor have reported use of maternal IVIG in a patient with a very high anti-D titer. The patient required several therapeutic plasma exchanges between weeks 12 and 14 of pregnancy. After the last therapeutic plasma exchange at 14 weeks, a loading dose 
of IVIG was given to the mother. She then received weekly IVIG infusions until 28 weeks' gestation. Anti-D titers were followed and remained stable throughout the remainder of the pregnancy. The mother delivered at 37 weeks' gestation and the infant had mild HD of the newborn, requiring IVIG and a red blood cell transfusion. ${ }^{39}$

\section{Conclusion}

IVIG is a safe and effective treatment for HDN that has gained in popularity over the last decade. It has been shown to decrease the need for exchange transfusion and, therefore the complications associated with exchanges. IVIG administration has been endorsed and included as a standard of practice in the American Academy of Pediatrics 2004 Management of Hyperbilirubinemia in the Newborn Infant guidelines. ${ }^{21}$ The use of IVIG in fetal medicine is progressing and will be followed as a possible treatment in the future.

\section{Disclosure}

The authors have no conflicts to report in interest in this work.

\section{References}

1. Hara T, Mizuno Y, Kawano M, Ueki Y, Ueda K. Treatment of immune hemolytic anaemia with gammaglobulin. J Pediatr. 1987;110(5): $817-818$.

2. Smith A, Sabio H, Bhatia JB, Kanto WP. Intravenous immunoglobulin (IVIG) in the management of isoimmune hemolytic anemia. $J$ Invest Med. 1997;45(1):39A.

3. Sato K, Hara T, Kondo T, Iwoa H, Honda S, Ueda K. High dose intravenous gammaglobulin therapy for neonatal immune haemolytic jaundice due to blood group incompatibility. Acta Paediatr Scand. 1991;80(2): $163-166$.

4. Rubo J, Albrecht K, Lasch P, et al. High-dose intravenous immune globulin therapy for hyperbilirubinaemia caused by $\mathrm{Rh}$ hemolytic disease. J Pediatr. 1992;121(1):93-97.

5. Ergaz Z, Arad I. Intravenous immunoglobulin therapy in neonatal immune hemolytic jaundice. J Perinat Med. 1993;21(3):183-187.

6. Dagoglu T, Ovali F, Samanci N, Bengisu E. High-dose intravenous immunoglobulin therapy for rhesus haemolytic disease. J Int Med Res. 1995;23(4):264-271.

7. Alpay E, Sarici SU, Okutan V, Erdem G, Ozcan O, Gokcay E. High-dose intravenous immunoglobulin therapy in neonatal immune haemolytic jaundice. Acta Paediatr. 1999;88(2):216-219.

8. Tanyer G, Siklar Z, Dallar Y, Yildirmak Y, Tiras U. Multiple dose IVIG treatment in neonatal immune hemolytic jaundice. JTrop Pediatr. 2001; 47(1):50-53.

9. Miqdad AM, Abdelbasit OB, Shaheed MM, Seidahmed MZ, Abomelha AM, Arcala OP. Intravenous immunoglobulin G (IVIG) therapy for significant hyperbilirubinemia in $\mathrm{ABO}$ hemolytic disease of the newborn. J Matern Fetal Neonatal Med. 2004;16(3):163-166.

10. Corvaglia L, Legnani E, Galletti S, Arcuri S, Aceti A, Faldella G. Intravenous immunoglobulin to treat neonatal alloimmune haemolytic disease. J Matern Fetal Neonatal Med. 2012;25(12):2782-2785.

11. Mundy CA. Intravenous immunoglobulin in the management of hemolytic disease of the newborn. Neonatal Netw. 2005;24(6):17-24.
12. Mollison PL, Engelfreit CP, Contreras M. Blood Transfusions in Clinical Medicine. 9th ed. Oxford, UK: Blackwell Scientific Publications; 1993.

13. Ziprin JH, Payne E, Hamidi L, Roberts I, Regan F. ABO incompatibility due to immunoglobulin $\mathrm{G}$ anti-B antibodies presenting with severe fetal anaemia. Transfus Med. 2005;15(1):57-60.

14. Maisel JM. Neonatal jaundice. Pediatr Rev. 2006;27(12):443-454.

15. Murray NA, Roberts IA. Haemolytic disease of the newborn. Arch Dis Child Fetal Neonatal Ed. 2007;92(2):F83-F88.

16. Howard H, Martlew V, McFadyen I, et al. Consequences for fetus and neonate of maternal red cell alloimmunisation. Arch Dis Child Fetal Neonatal Ed. 1998;78(1):F62-F66.

17. Stockman JA, de Alarcon PA. Overview of the state of the art of Rh disease: history, current clinical management and recent progress. J Pediatr Hematol Oncol. 2001;23(8):385-393.

18. Thompson J. Haemolytic disease of the newborn: the new NICE guidelines. J Fam Health Care. 2002;12(5):133-136.

19. Zantek ND, Koepsell SA, Tharp DR, Cohn CS. The direct antiglobulin test: a critical step in the evaluation of hemolysis. Am J Hematol. 2012;87(7):707-709.

20. Dinesh D. Review of positive direct antiglobulin tests found on cord blood sampling. J Paediatr Child Health. 2005;41(9-10):504-507.

21. American Academy of Pediatrics. Management of hyperbilirubinemia in the newborn infant 35 or more weeks of gestation. Pediatrics. 2004;114(1):297-316.

22. Watson RL. Gastrointestinal disorders. In: Deacon J, O'Neill P, editors. Core Curriculum for Neonatal Intensive Care Nursing. 2nd ed. Philadelphia, PA, USA: WB Saunders; 1999.

23. Jackson JC. Adverse events associate with exchange transfusion in healthy and ill newborns. Pediatrics. 1997;99(5):E7.

24. Gammagard Liquid ${ }^{\circledR}$ (immune globulin infusion, human 10\%) [package insert]. Westlake Village, CA, USA: Baxter; 2015.

25. Gordon S. Mononuclear phagocytes in immune defense. In: Roitt I, Brostroff J, Male D, editors. Immunology. 6th ed. St Louis, MO, USA: Mosby; 2001.

26. Newland A. High-dose $\mathrm{IgG}$ in adults with autoimmune thrombocytopenia. Lancet. 1983;1(8316):84-87.

27. Urbaniak SJ. ADCC (K-cell) lysis of human erythrocytes sensitized with rhesus alloantibodies. II. Investigation into the mechanism of lysis. Br J Haematol. 1979;42(2):315-325.

28. Ergaz Z, Gross D, Bar-Oz B, Peleg O, Arad I. Carboxyhemoglobin levels in neonatal immune hemolytic jaundice treated with intravenous gammaglobulin. Vox Sang. 1995;69(2):95-99.

29. Alcock GS, Liley H. Immunoglobulin infusion for isoimmune haemolytic jaundice in neonates. Cochrane Database Syst Rev. 2002;3: CD003313.

30. Copelan EA, Strohm PL, Kennedy MS, Tutschka PJ. Hemolysis following intravenous immune globulin therapy. Transfusion. 1986;26(5): 410-412.

31. Magny JF, Bremard-Oury C, Brault D, et al. Intravenous immunoglobulin therapy for prevention of infection in high-risk premature infants: report of a multicenter, double blind study. Pediatrics. 1991;88(3): 437-443.

32. Navarro M, Negre, S, Matoses ML, Golombek SG, Vento M. Necrotizing entercolitis following the use of intravenous immunoglobulin for haemolytic disease of the newborn. Acta Paediatr. 2009;98(7): 1214-1217.

33. Figueras-Aloy J, Rodriguez-Miguelez JM, Iriondo-Sanz M, SalviaRoiges MD, Botet-Mussons F, Carbonell-Estrany X. Intravenous immunoglobulin and necrotizing entercolitis in newborns with hemolytic disease. Pediatrics. 2010;125(1):139-144.

34. Smits-Wintjens VE, Walther FJ, Rath ME, et al. Intravenous immunoglobulin in neonates with rhesus hemolytic disease: a randomized controlled trial. Pediatrics. 2011;127(4):680-686.

35. Gottestein R, Cooke RW. Systematic review of intravenous immunoglobulin in haemolytic disease of the newborn. Arch Dis Child Fetal Neonatal Ed. 2003;88(1):F6-F10. 
36. Huizing $\mathrm{K}$, Roislien J, Hansen T. Intravenous immune globulin reduces the need for exchange transfusion in Rhesis and ABO incompatibility. Acta Paediatr. 2008;97(10):1362-1365.

37. Kriplani A, Singh BM, Mandal K. Fetal intravenous immunoglobulin therapy in Rhesus hemolytic disease. Gynecol Obstet Invest. 2007;63(3): $176-180$.

38. Matsuda H, Yoshida M, Wakamatu H, Furuya K. Fetal intraperitoneal injection of immunoglobulin diminishes alloimmune hemolysis. J Perinatol. 2011;31(4):289-292.
39. Bellone M, Boctor F. Therapeutic plasma exchange and intravenous immunoglobulin as primary therapy for D alloimmunization in pregnancy precludes the need for intrauterine transfusion. Transfusion. 2014;54(8):2118-2121.

\section{Publish your work in this journal}

International Journal of Clinical Transfusion Medicine is an international, peer-reviewed, open access, online journal publishing clinicalexperimental, policy-making and evidence-based practices of all topics pertaining to clinical transfusion medicine. Original research, short reports, reviews, case reports and commentaries are invited.
The manuscript management system is completely online and includes a very quick and fair peer-review system, which is all easy to use. Visit http://www.dovepress.com/testimonials.php to read real quotes from published authors.

\footnotetext{
Submit your manuscript here: http://www.dovepress.com/international-journal-of-clinical-transfusion-medicine-journal
} 